\title{
Development of an Internet of Things (IOT) Enable Smart Parking System for Sri Lanka
}

\section{H.D.D. Maduranga}

THE NATIONAL SCHOOL OF BUSINESS MANAGEMENT

K.G.T.U. Imendra

THE NATIONAL SCHOOL OF BUSINESS MANAGEMENT

R.D.D. Prematilake ( $\square$ ruveendradeewshan@gmail.com )

THE NATIONAL SCHOOL OF BUSINESS MANAGEMENT

\section{S.D. Samarasekara}

THE NATIONAL SCHOOL OF BUSINESS MANAGEMENT

\section{R.B.S. Wanninayake}

THE NATIONAL SCHOOL OF BUSINESS MANAGEMENT

\section{A. Perera}

THE NATIONAL SCHOOL OF BUSINESS MANAGEMENT

\section{Method Article}

Keywords: Smart City, loT, Smart parking, Firebase, Mobile App

Posted Date: September 20th, 2021

DOl: https://doi.org/10.21203/rs.3.rs-677449/v2

License: (c) (i) This work is licensed under a Creative Commons Attribution 4.0 International License. Read Full License 


\title{
Development of an Internet of Things (IoT) Enable Smart Parking System for Sri Lanka
}

\author{
H.D.D. Maduranga, K.G.T.U. Imendra, R.D.D. Prematilake, S.D. Samarasekara, R.B.S. \\ Wanninayake, A. Perera \\ The National School of Business Management, Colombo- Sri Lanka.
}

\begin{abstract}
Although the smart parking system is not a new concept for Sri Lankans, the idea of booking parking slots in advance and then parking is a novice theme for our country. So, we decided to see that novice theme as a new opportunity and used this concept for our study title, As the first phase of the study, we agreed to design a remote reservation parking system for a public parking area. We designed an online parking reservation mobile application system that shows the available free parking slots to the users where the users can reserve a parking slot for any time they want. IoT-enabled mobile app technology was used to develop the system. Results show promising results applying such a system to local parking stations in Sri Lanka.
\end{abstract}

Keywords: Smart City, IoT, Smart parking, Firebase, Mobile App

\section{Introduction}

The "SMART concept" integrates Information and Communication Technology (ICT) and various electronic devices connected to the IoT (Internet of Things) to optimize the efficiency of city transportations and its related services. "SMART concept" is now a very important goal setting in our society and the developing IoT field is making it very achievable to make it a reality. With the growth of technology, the concept of the Internet of Things (IoT) and deep learning can be used in the planning of Smart cities which can gradually tackle urban mobility problems and can also help to provide a sustainable infrastructure economically, ecologically, and socially to the citizens. Sustainable Urban Mobility and reducing traffic congestion are some of the most critical 
challenges of urban development especially in the case of limited availability of parking space. At present, many intelligent systems mostly in the form of mobile applications help drivers by reporting traffic jams, road conditions, accidents, and alternative routes.

For the PUSL2008, Internet of Things module we decided to develop a project that is a novel for our country, Sri Lanka. We are going to develop a remote reservation parking system for a public place as the first phase of the project plan and in here the main functionality of this system is monitoring the status of every parking slots available in the parking and updating it to the database so that the users can see the status of the parking slots from the mobile application and book them per there necessity prior to the visit, rather than the traditional way of visiting the parking and checking the free slots and then finding free parking slots to park.

Although smart parking systems already exist in Sri Lanka, they only facilitate the parking slot when vehicles arrive at the parking area. This smartness is only limited to the parking site. These days people cannot afford their time getting wasted by turning around to visit another parking site when the visited parking is full. This current smart parking is not satisfying the requirement of the usual busy lifestyle of the people of this generation. As a solution for this problem, we connect people with the parking site before the visit. The possibility of booking ahead of the parking slots from home or any other places before arriving at the designated parking area is a new theme for Sri Lankan people and this is the main area we are focusing on in our system. We use an online reservation mobile application system for the reservation of the parking slots. The users can log in to the system and look for the remaining free slots of the parking area and they can include a time period and reserve the relevant parking slot for a certain time period. This makes a significant difference from the traditional parking systems.

\section{Methodology}

In this study we are mainly focused on development of a mobile app based IoT system for smart parking in Sri Lanka, the following aspects were considered when developing the system.

1. Sensor Integration through Embedded System: The sensor-integrated parking architecture is used for verifications and data collecting. 
2. Firebase Fire store Cloud through internet connectivity: Vehicle license plate number, user details, and reservation details are sent to the firebase database.

3. Data Should store in the cloud for accessing them from different users: Firebase store the details of the status of the parking slot so that the users like the administrator and the drivers can access and reserve their prerequisite.

4. Administration activities: In our remote reservation system, we have an administrator who has admin privileges like monitoring of the parking slots, reserving slots, getting alerted when the wrong vehicle parks in the wrong parking lot, etc. The administrator can view some user data to a certain extent where other normal users cannot access it.

5. Mobile Application Development for the Users: Mobile application systems dedicated to the remote reservation system facilitate the operations and management between the parking area, user, and the administrator.

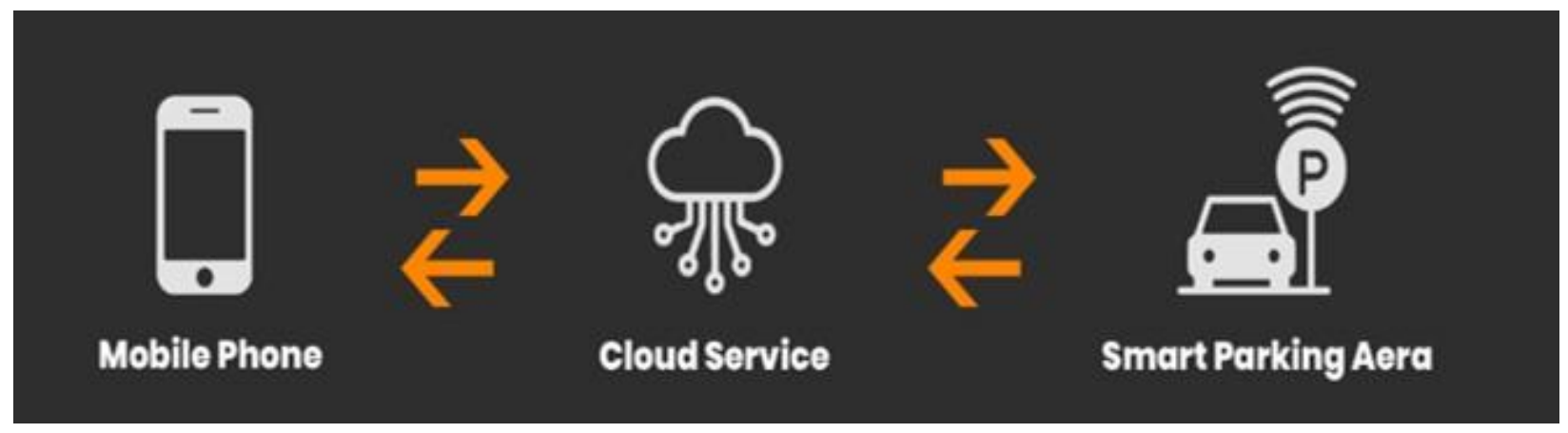

Figure 1: Proposed System Architecture

Figure 1 depicts the proposed system architecture. Prior to the parking, the user has to reserve a parking slot through the mobile application. First of all, the user has to register to the system. During the reservation of the parking slot, the user has to enter the vehicle plate number, time period to be reserved. Once the parking slot is reserved, the parking slot Id gets connected with the vehicle plate number. Later relevant users can park during the reservation time period. If any user does not possess a smart device that can do the reservation, they can contact the administrator and reserve a slot by giving required personal details.

When the vehicle approaches the parking area, the barrier of the parking gets automatically opened when the vehicle is nearby the entrance. This parking barrier opening-closing mechanism is achieved through ultrasonic sensor detection and server motors collectively. Ultrasonic sensors can detect the approaching motor vehicle, then the server motors get triggered to open the gate. Arrived passenger get directed to the 
reserved parking slot. In here, real-time video footage of the arrived vehicle is accessed through the CCTV cameras. With the help of machine learning, we trace the arrived vehicle plate number then it is subjected to verification. This tracing is done using OpenCV and YOLO libraries with the help of the python programming language. If the reserved vehicle plate number matches with the arrived vehicle plate number user (driver) can park without any interruptions. If the verification is not matched administrator gets notified and that driver has to leave the specific parking slot and move to the assigned parking slot in the parking space. Table 1 depicts the hardware and software requirement for the development of the system.

Table 1: Software Requirement of The Proposed System

\begin{tabular}{|l|l|}
\hline Hardware Requirement & Software Requirement \\
\hline Server motors. & IDE: Arduino IDE, Visual studio \\
Bread board. & code - python, Android Studio. \\
Ultra-sonic sensors. & Mobile UI framework: Flutter \\
Jump wires. & Programming Language: C/C++, \\
CCTV camera & Python, Dart \\
Arduino Uno. & Database: Google Firebase \\
& \\
\hline
\end{tabular}

\section{Result Windows}

At first users are introduced with the login page (Figure 1), depending on the account users can login as an admin or a normal user, if a user doesn't have an account, they can register via the register now button and it'll direct to the registration page. When a user is logged in, they can see the layout of the carpark and in its users have the ability to reserve a slot and view all the reserved slots and also view if a car is parked on a specific slot or not.

Admin accounts are flagged within the application and when an admin is logged into the application, they also get the same window as users but with added functionalities. When a certain slot is reserved, admin can see the license plate number, if a wrong vehicle is parked on a reserved slot admin can see both numbers plates the reserved vehicle and the miss directed vehicle, admin can also view the duration of last vehicle that was parked on a slot and its charge

Application is tested on 4 parking slots as shown in the Figure 2, data for each slot is taken from Firestore Realtime Database it has been tested when a vehicle is parked on a slot the information is registered in the 
database and the license plate numbers are accurately taken for all the 4 slots and the application is tested on many different mobile devices and 5 different user accounts and everything appeared to work normal.
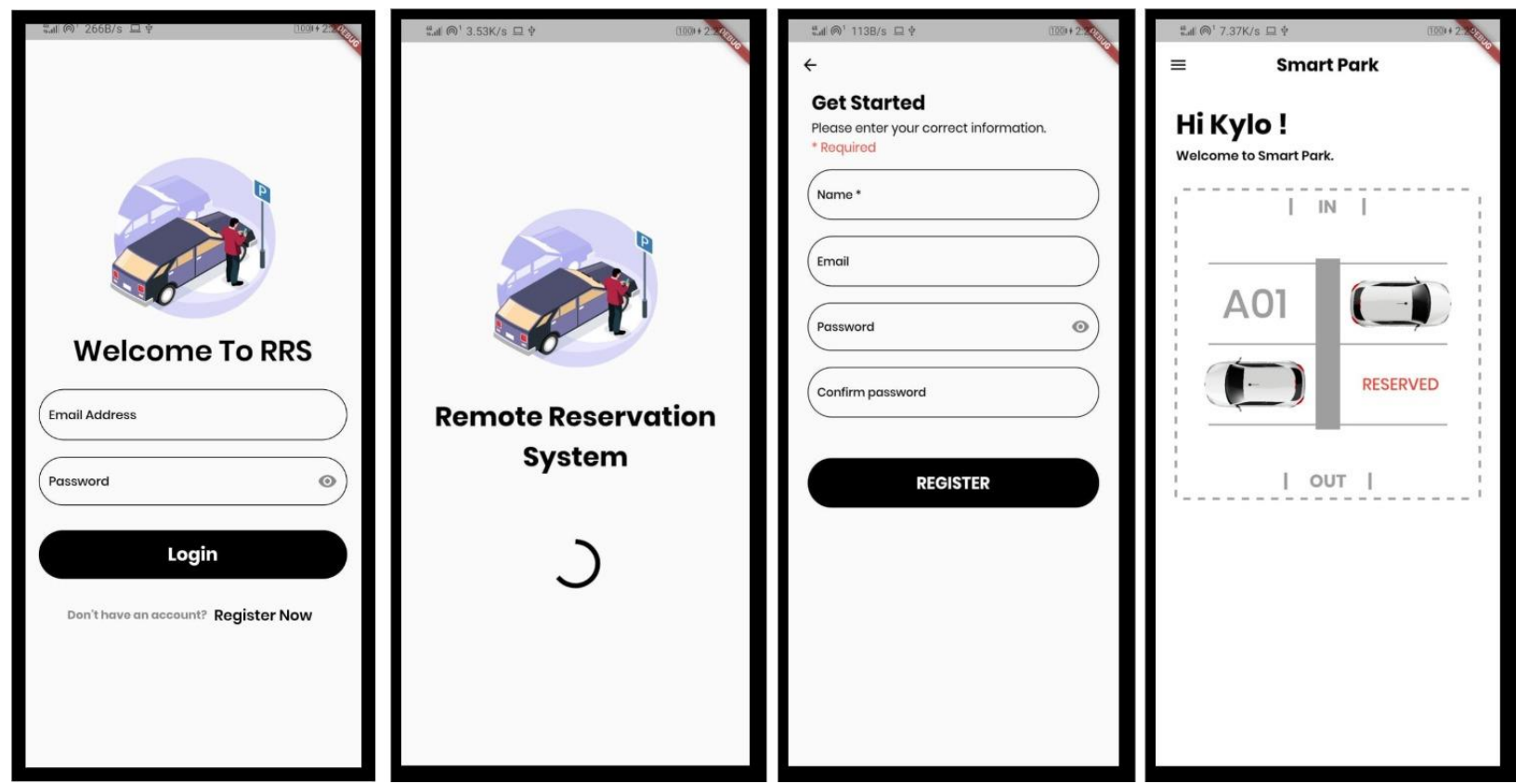

Figure 2: Result Windows of The Mobile App - User Side

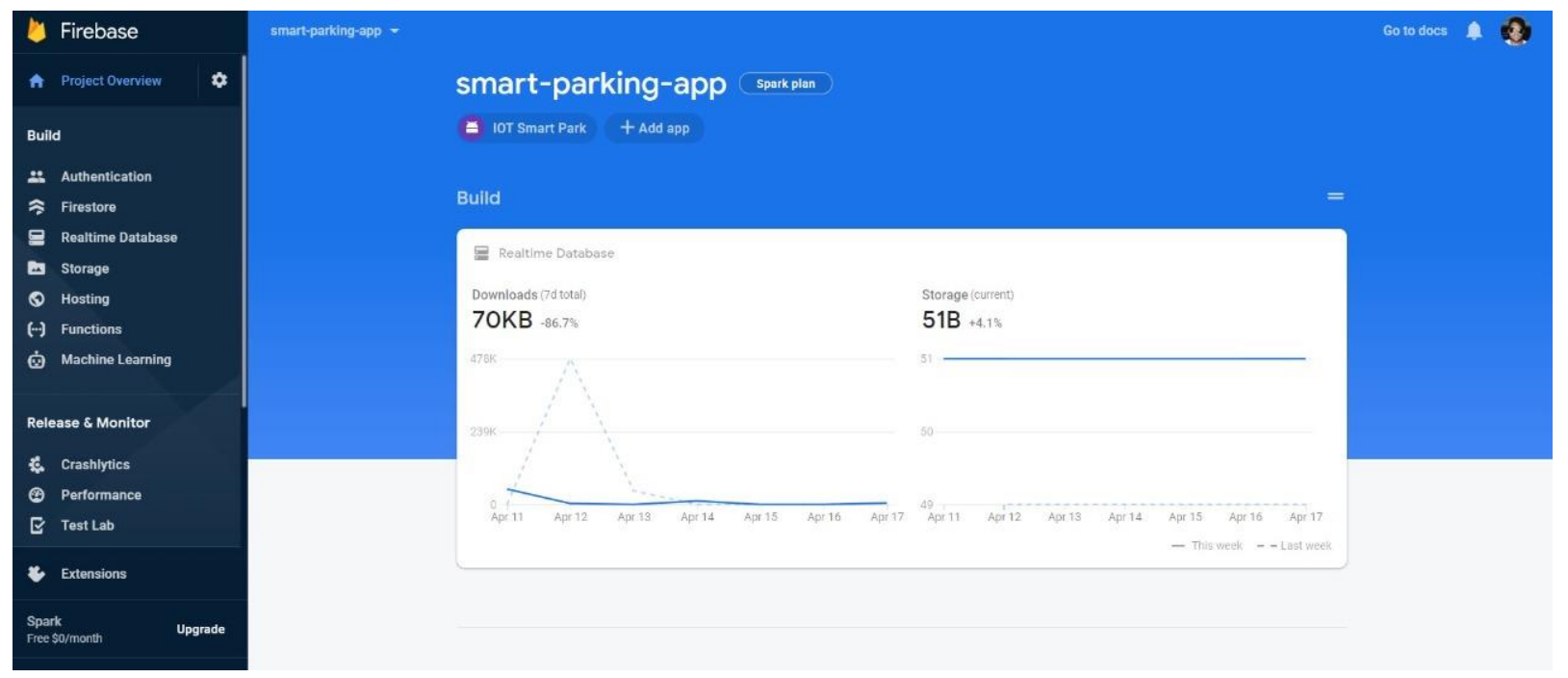

Figure 3: Result Window of The Firebase - Admin Side

\section{Conclusion}

According to the NUMBEO website, Sri Lanka is the world's 4th top country with the highest traffic jams and most of these traffic jams are caused by the parking issues in our country. Sometimes the roads are 
blocked because of the illegal ways the vehicles are parked because they could not find proper parking places or, they go around and round till they find a parking spot causing the traffic jams in the roads. As a solution, we suggest "remote reservation parking system" where the passengers can book or reserve a parking spot near to the place they are visiting ahead of time, and there will be no traffic jams caused due to improper parking or insufficient traditional parking systems. So, we think "remote reservation parking system" will be a good solution for this traffic jam and parking problem in Sri Lanka and also in the world as well. So, this "remote reservation parking system" overall is a successful project.

\section{Competing Interests}

The authors declare no competing interests.

\section{References}

1. Khanna, A., \& Anand, R. (2016, January). IoT based smart parking system. In 2016 International Conference on Internet of Things and Applications (IOTA) (pp. 266-270). IEEE.

2. Soni, V. D. (2018). IOT Based Parking Lot. International Engineering Journal for Research \& Development, 3(1), 9-9.

3. Shinde, S., Patil, A., Chavan, S., Deshmukh, S., \& Ingleshwar, S. (2017, February). IoT based parking system using Google. In 2017 International Conference on I-SMAC (IoT in Social, Mobile, Analytics and Cloud) (I-SMAC) (pp. 634-636). IEEE.

4. Karunachandra, R. T. H. S. K., \& Herath, H. M. K. K. M. B. (2021). Binocular VisionBased Intelligent 3-D Perception for Robotics Application.

5. Sadhukhan, P. (2017, September). An IoT-based E-parking system for smart cities. In 2017 International conference on advances in computing, communications and informatics (ICACCI) (pp. 1062-1066). IEEE.

6. Herath, H. M. K. K. M. B., Karunasena, G. M. K. B., \& Herath, H. M. W. T. (2021). Development of an IoT Based Systems to Mitigate the Impact of COVID-19 Pandemic in Smart Cities. In Machine Intelligence and Data Analytics for Sustainable Future Smart Cities (pp. 287-309). Springer, Cham.

7. Mainetti, L., Patrono, L., Stefanizzi, M. L., \& Vergallo, R. (2015, December). A Smart Parking System based on IoT protocols and emerging enabling technologies. In 2015 IEEE 2nd World Forum on Internet of Things (WF-IoT) (pp. 764-769). IEEE.

8. Herath, H. M. K. K. M. B. (2021). Internet of Things (IoT) Enable Designs for Identify and Control the COVID-19 Pandemic. In Artificial Intelligence for COVID-19 (pp. 423436). Springer, Cham.

9. Lookmuang, R., Nambut, K., \& Usanavasin, S. (2018, May). Smart parking using IoT technology. In 2018 5th International Conference on Business and Industrial research (ICBIR) (pp. 1-6). IEEE. 
10. Luque-Vega, L. F., Michel-Torres, D. A., Lopez-Neri, E., Carlos-Mancilla, M. A., \& González-Jiménez, L. E. (2020). Iot smart parking system based on the visual-aided smart vehicle presence sensor: SPIN-V. Sensors, 20(5), 1476.

11. Herath, H. M. K. K. M. B., Ariyathunge, S. V. A. S. H., \& Priyankara, H. D. N. S. (2020). Development of a Data Acquisition and Monitoring System Based on MODBUS RTU Communication Protocol. Development, 5(6).

12. Herath, H. M. K. K. M. B., Prematilake, R. D. D., \& Madhusanka, B. G. D. A. (2022). Integration of Fog Computing and IoT-Based Energy Harvesting (EHIoT) Model for Wireless Sensor Network. In Energy Conservation Solutions for Fog-Edge Computing Paradigms (pp. 215-231). Springer, Singapore.

13. Lakshmi, K., \& Gayathri, S. (2017). Implementation of IoT with image processing in plant growth monitoring system. Journal of Scientific and Innovative Research, 6(2), 8083.

14. Sharma, A., Singh, P. K., \& Kumar, Y. (2020). An integrated fire detection system using IoT and image processing technique for smart cities. Sustainable Cities and Society, 61, 102332.

15. Frank, A., Al Aamri, Y. S. K., \& Zayegh, A. (2019, January). IoT based smart traffic density control using image processing. In 2019 4th MEC International Conference on Big Data and Smart City (ICBDSC) (pp. 1-4). IEEE. 
Figures

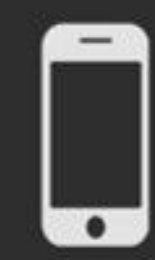

Mobile Phone

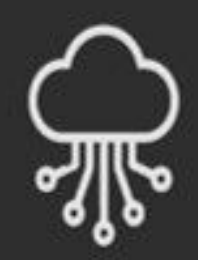

Cloud Service
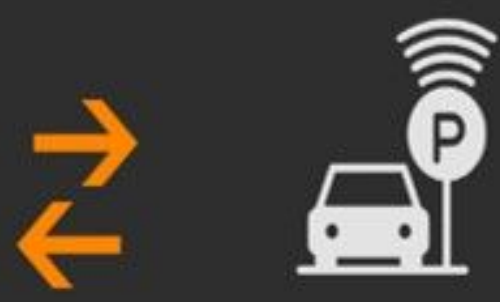

Smart Parking Aera

Figure 1

Proposed System Architecture
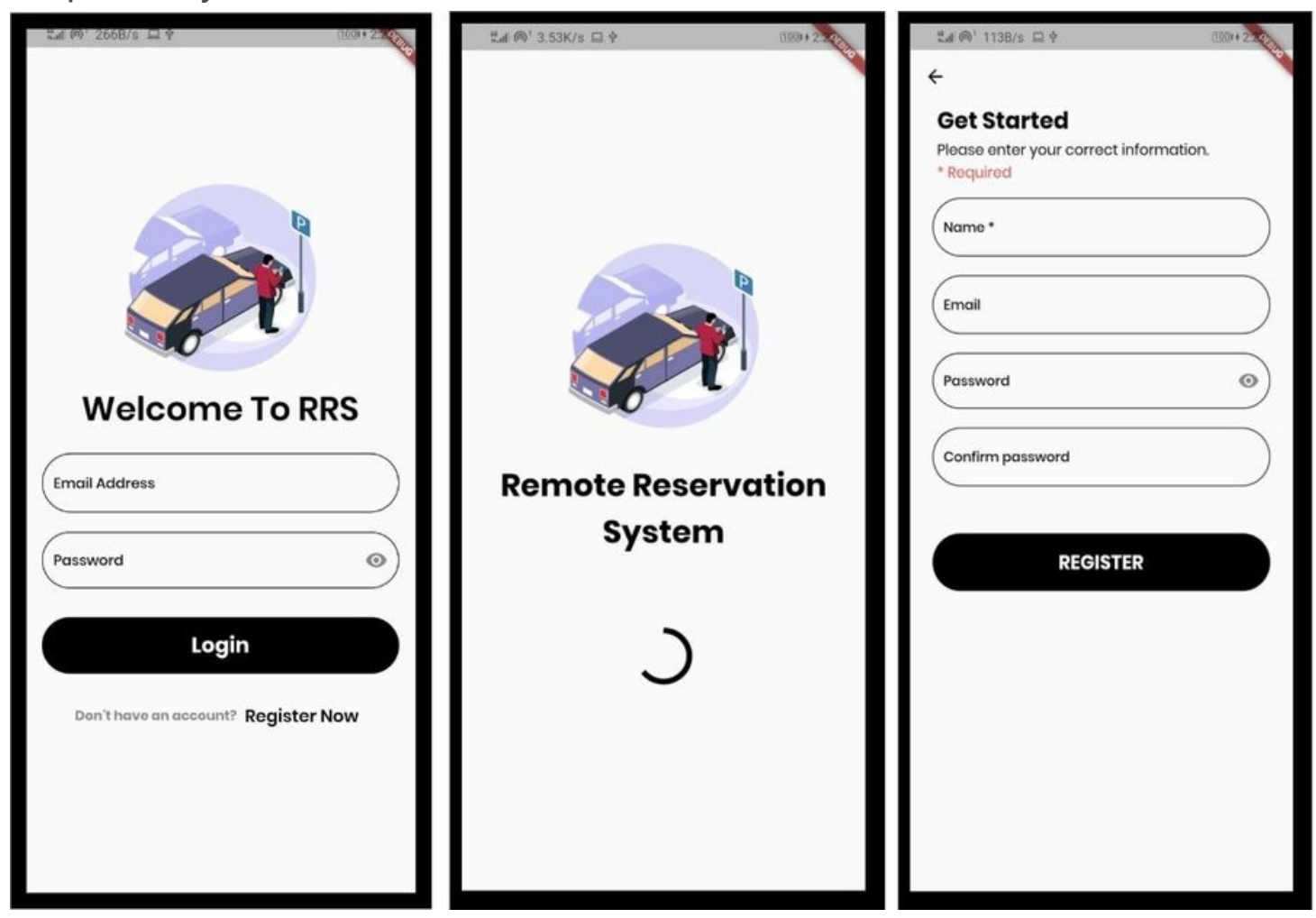

Figure 2

Result Windows of The Mobile App - User Side 


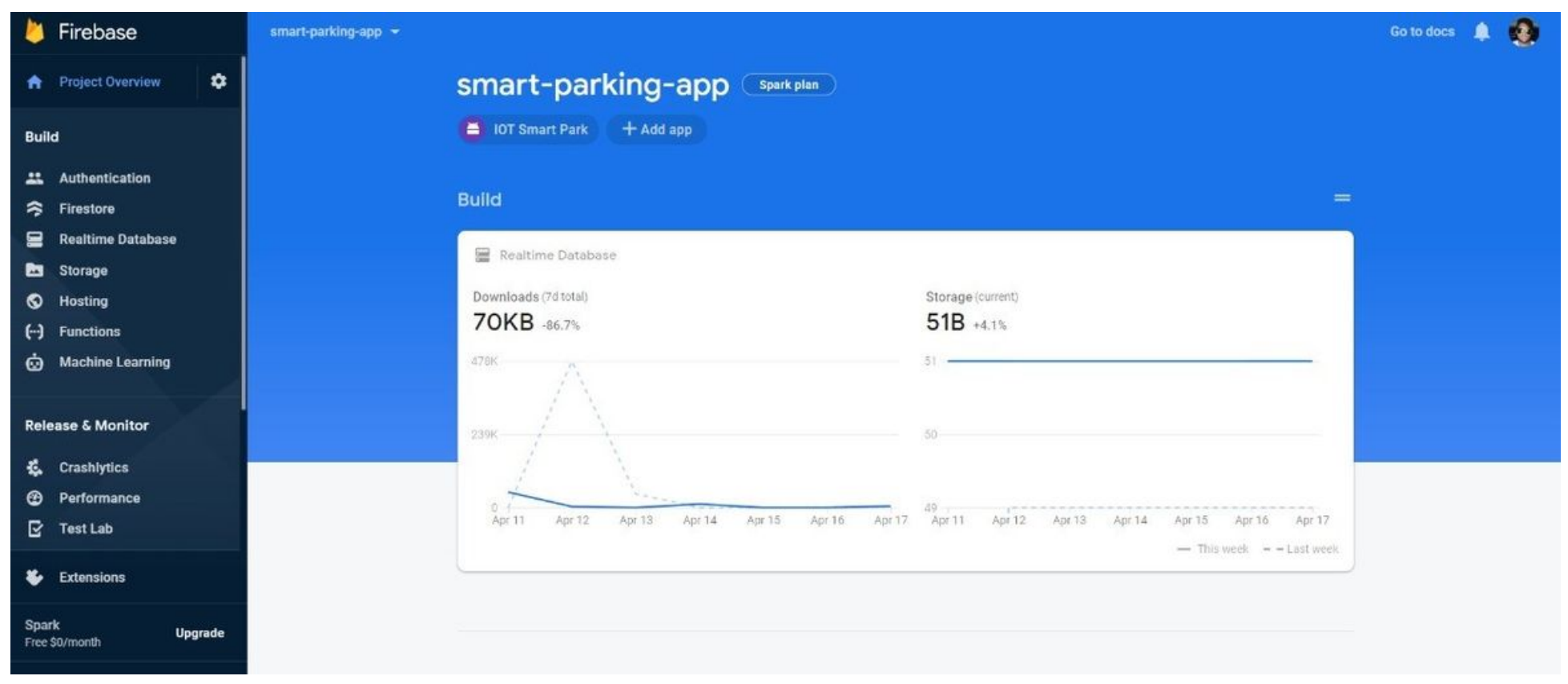

\section{Figure 3}

Result Window of The Firebase - Admin Side 